\title{
Histologia da glândula parotoide de anuros da espécie Rhinella schneideri (Amphibia: Bufonidae)
}

\author{
Juliana Costa Sousa ${ }^{1}$ \\ Regina Lúcia dos Santos Silva ${ }^{1}$ \\ Richard Átila de Sousa ${ }^{1}$ \\ Mauro Sergio Cruz Souza Lima ${ }^{2}$ \\ Guilherme José Bolzani de Campos Ferreira ${ }^{1 *}$ \\ ${ }^{1}$ Curso de Medicina Veterinária, Universidade Federal do Piauí, Campus "Prof. Cinobelina Elvas" \\ BR 135, Km 03, Planalto Horizonte, CEP 64900-000, Bom Jesus - PI, Brasil \\ ${ }^{2}$ Curso de Licenciatura em Ciências Biológicas, Universidade Federal do Piauí \\ Campus "Amílcar Ferreira Sobral”, BR 343, Km 3,5, CEP 64800-000, Floriano - PI, Brasil \\ * Autor para correspondência \\ guilherme.ferreira@ufpi.edu.br
}

Submetido em 20/11/2014

Aceito para publicação em 06/02/2015

\section{Resumo}

O estudo histológico da glândula parotoide foi realizado utilizando 10 exemplares (machos e fêmeas) da espécie Rhinella schneideri, capturados manualmente em coletas noturnas no município de Bom Jesus, Piauí. Posteriormente, foram eutanasiados por administração de uma dose letal de anestésico Tiopental e seguidamente as glândulas parotoides foram coletadas e submetidas a processamento histológico padrão com inclusão em parafina e os blocos seccionados em micrótomo rotativo manual a espessura de $4 \mu \mathrm{m}$. Diante da escassez de informações sobre condições anátomo-histológica de Rhinella scheneideri, buscou-se abordar as principais características marcantes das macroglândulas encontradas na espécie, conhecimento importante para compreensão do funcionamento deste mecanismo de defesa da espécie. Histologicamente, evidenciamos a presença dos alvéolos das macroglândulas, com presença de ductos circundados com células mucosas diferenciadas, as "glândulas acessórias", sendo também encontradas glândulas granulosas. Verificou-se ainda que cada glândula possui ductos que comunicam o corpo glandular com o meio exterior, sendo o ducto revestido internamente por células epiteliais glandulares do próprio ducto, constituindo um plug, que em Rhinella schneideri promove a obstrução total do ducto. Essas macroglândulas não apresentam diferenciação histológica quando se comparado a outras espécies da família Bufonidae.

Palavras-chave: Anatomia; Anfíbios; Anuros; Ducto; Macroglândulas

\section{Abstract}

Histology of parotoid gland of Anuran species Rhinella schneideri (Amphibia: Bufonidae). We performed histologic evaluation of the parotid glands of 10 (male and female) Rhinella schneideri. Animals were manually captured during nocturnal collections in Bom Jesus, Piauí, and euthanized by administering a lethal dose of anesthetic thiopental. The parotid glands were then collected and embedded in paraffin, and sectioned to 4 
$\mu \mathrm{m}$ blocks using a manual rotary microtome. Considering the lack of general information concerning anatomical and histological conditions of Rhinella scheneideri, we sought to address key characteristics of macro glands found in the species with the goal of a better understanding of the operation of this type of defense mechanism. Histological analysis revealed the presence of macrogland alveoli with ducts encircled with differentiated mucous cells, known as "accessory glands", as well as granular glands. We also discovered glandular ducts on the glands which communicate with the outside of the body. These ducts are internally lined by duct glandular epithelial cells, forming a plug which promotes total obstruction of the duct. There were no histological differences in macro gland anatomy in this species compared to other species in Bufonidae.

Key words: Anatomy; Amphibians; Duct; Frogs; Macro glands

\section{Introdução}

Os anfíbios, em especial os anuros são os vertebrados mais susceptíveis à alteração ambiental, por serem animais ectodérmicos e possuírem pele permeável. Essas alterações naturais ou antrópicas são consideradas fatores responsáveis pelo declínio das populações dessas espécies em escala global (HADDAD; ABE, 2000).

A Família Bufonidae é composta por 70 espécies, segundo Bastos et al. (2003), e é conhecida como a dos sapos verdadeiros ou popularmente sapo cururu. Esta família apresenta como principais características morfológicas, a presença de uma grande glândula parotoide ao lado da cabeça e geralmente tubérculos na pele na parte dorsal do corpo (VIEIRA, 2010).

Rhinella schneideri é um típico representante da família Bufonidae, e como a maioria das espécies de Rhinella, é terrestre e possui um ativo forrageador com uma dieta diversificada e ampla distribuição geográfica, podendo ser encontrado no centro sul do Brasil, na Argentina, Bolívia, Paraguai e Uruguai (FROST, 2011; AQUINO et al., 2014).

A pele dos anfíbios é caracterizada pela presença de inúmeras glândulas granulosas (ou de veneno). Tais glândulas podem se distribuir por todo o corpo, ou ainda, acumular-se em determinadas regiões, proporcionalmente estratégicas posicionadas contra a ação de predadores. Quando importunados, os sapos inflam o corpo e posicionam as suas parotoides em direção ao agressor. O envenenamento, entretanto, só ocorre, se o predador morder o sapo e a secreção das glândulas entrar em contato principalmente com a sua mucosa oral, configurando a defesa passiva típica dos anfíbios não sendo então lesiva a espécie humana visto que os anuros só apresentam essa reação ao serem comprimidos manualmente ou mordidos. Em outras espécies podemos ter resultados diferentes desse mecanismo de defesa como, por exemplo, no sapo amazônico Rhaebo guttatus, que apresenta um comportamento tipicamente ativo capaz de ejetar seu veneno voluntariamente a grandes distâncias, através de suas parotoides (FONTANA, 2012).

Especificamente nos Bufonídeos, a pele e a característica da glândula parotoide são aspectos muito utilizados para fins de classificação. No entanto essa área de pesquisa ainda necessita de um amplo estudo para verificação das variáveis qualitativas (tamanho da espécie, peso, idade, maturidade, clima, entre outras), visto que a morfologia do corpo apresenta poucas diferenças, dificultando assim a identificação por meio de uma análise superficial, induzindo, necessariamente a realização de uma análise mais precisa, por exemplo, nos tamanhos relativos dos artelhos (RIBEIRO et al., 2005).

Tais estruturas glandulares são classificadas basicamente em dois tipos: glândulas granulosas (também conhecidas como glândulas de veneno) e glândulas mucosas. As mucosas são acinares, formadas por uma camada simples de células secretoras, apresentando sua luz bem definida. Segundo Dapson (1970), a secreção das glândulas mucosas é composta principalmente por glicosaminoglicanas e proteoglicanas. Por outro lado, as glândulas granulosas secretam uma variedade de substâncias, geralmente pertencentes a quatro categorias de compostos: aminas biogênicas, alcaloides, esteroides e proteínas (TOLEDO; JARED, 1995; CLARKE, 1997), variando de forma qualitativa e quantitativa entre as espécies. Divergindo a morfologia das glândulas de secreção de venenos entre os animais, essas glândulas, 
nos anuros, é constituída por uma massa citoplasmática multinucleada, o que caracteriza a sua natureza sincicial. Não apresentam lúmen e a secreção é acumulada no interior das glândulas, sendo liberada através de um ducto epidérmico da glândula (DELFINO, 1991; TERRENI et al., 2003).

Tendo em vista a escassez de trabalhos específicos sobre a histologia da glândula parotoide da Rhinella schneideri, buscou-se abordar as principais características marcantes das macroglândulas encontradas na espécie sendo de suma importância para então compreendermos como funciona o mecanismo de defesa utilizado por essas espécies.

\section{Material e Métodos}

Foram coletados dez exemplares (dentre estes machos e fêmeas) da espécie Rhinella schneideri, capturados manualmente por coletas noturnas na cidade de Bom Jesus, Piauí, Brasil (94'19.04”S/ 44²1'5.54”O). Os animais capturados foram mantidos em terrários contendo terra e água para evitar desidratação, além de galhos e folhas retirados do seu ambiente natural a fim de simulá-lo e reduzir o estresse. Após o período de aclimatização, foram eutanasiados por administração de dose letal de Tiopental, conforme recomendado na Resolução nº 1000/2012 do Conselho Federal de Medicina Veterinária e pela Associação Americana de Médicos Veterinários (AVMAPANEL ON EUTHANASIA, 2001; CFMV, 2012) e aprovado pelo Comitê de Ética Animal da Universidade Federal do Piauí (Parecer no 084/12) e SISBIO (no 28629-1). Após a eutanásia dos animais, foram coletados fragmentos das glândulas parotoides fixados em solução aquosa de formaldeído tamponada a $10 \% \mathrm{com} \mathrm{pH}$ 7,0, permanecendo nesta solução por 72 horas.

Em sequência a fixação da glândula parotoide, procedeu-se à lavagem em água corrente por duas horas e iniciou-se a desidratação em álcool $70^{\circ}$ (over night) e posterior desidratação em série alcoólica crescente $\left(80^{\circ}\right.$, $90^{\circ}, 95^{\circ}, 100^{\circ} \mathrm{I}, 100^{\circ} \mathrm{II}$ e $\left.100^{\circ} \mathrm{III}\right)$ com intervalos de 60 minutos, diafanização em série de xilol (Xilol I, Xilol II), infusão de parafina a $60^{\circ} \mathrm{C}$ em duas etapas de 60 minutos e finalizando com a inclusão em parafina para confecção de blocos.
A secção foi realizada em um micrótomo rotativo manual (Lupe $\left.{ }^{\circledR}\right)$ com navalha descartável de perfil alto (Leica ${ }^{\circledR} 818$ ) a espessura de $4 \mu \mathrm{m}$ e $\log \mathrm{o}$ confeccionadas as lâminas, que foram coradas pela técnica da Hematoxilina-Eosina (HE), montadas com lamínulas e Bálsamo do Canadá, sendo os cortes histológicos analisados e fotomicrografados com uma câmara digital de 2 megapixels (DEM200 Digital Eyepiece for Microscope - Scopetek $\left.{ }^{\circledR}\right)$ acoplada a um microscópio biológico (BEL Photonics ${ }^{\circledR}$ ).

$\mathrm{Na}$ análise histológica, deu-se ênfase as seguintes características: estrutura geral do órgão e os constituintes da glândula como, tipos glandulares e celulares de acordo com a composição histológica do órgão descrito.

\section{Resultados}

Macroscopicamente pode-se observar que as glândulas parotoides de Rhinella schneideri localizam-se caudalmente ao tímpano e dorsolateralmente a escápula (Figura 1).

Histologicamente a epiderme do tegumento dorsal de Rhinella scheneideri é formada por camadas celulares, encontrando-se na parte mais superficial células achatadas e queratinizadas. Abaixo desta camada verificam-se células poliédricas e ainda, apoiados a lâmina basal pode-se observar uma camada de células colunares (Figura 2A). Já na derme observa-se duas camadas de tecido conjuntivo: o estrato esponjoso contendo vasos sanguíneos e glândulas (Figura 2A), e o estrato compacto que contém fibras colágenas (Figura 2B), podendo especificar que entre as duas camadas tem-se a camada calcificada, interrompida por fibras e livre de células (Figura 2B e 3).

As glândulas granulosas (Glândulas de veneno) não possuem lúmen e são sinciciais (Figura 2A). Ambos os tipos glandulares se conectam com o exterior através de ductos epidérmicos por onde a secreção é liberada na superfície corporal e são envolvidos por uma monocamada de células mioepiteliais, que é mais desenvolvida nas glândulas granulosas. As glândulas mucosas são acinares apresentando luz bem definida e formada também por células mioepiteliais. 
FIGURA 1: Fotomacrografia de um exemplar de Rhinella schneideri (fêmea), evidenciando a localização da glândula parotoide ( $\leftarrow$ ) e o tímpano $(*)$.

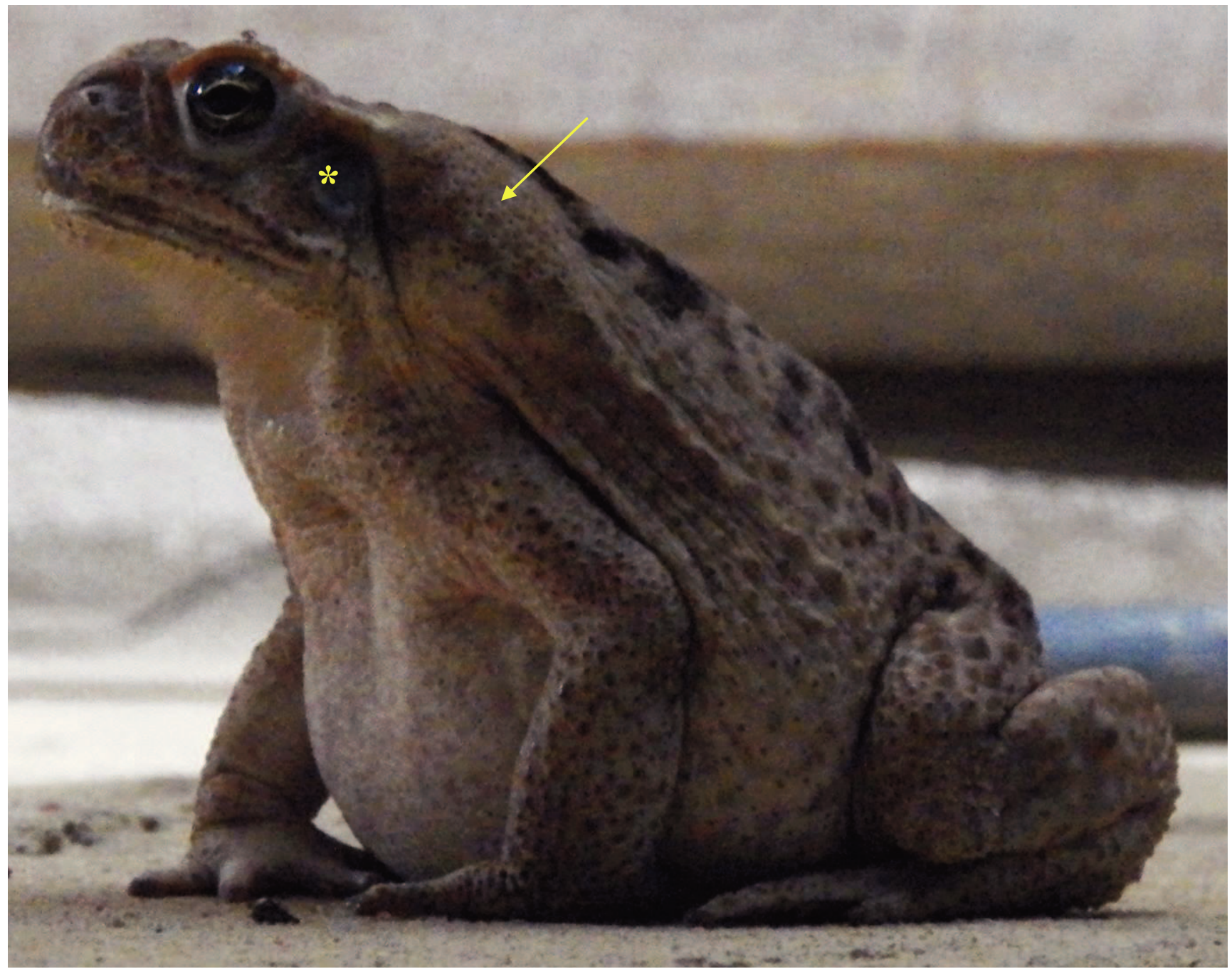

Cada unidade secretora da parotoide possui um ducto que comunica o corpo glandular com o exterior. Esse ducto é revestido por células epiteliais glandulares do próprio ducto, constituindo um plug. Em Rhinella schneideri, o plug é responsável pela obstrução total do ducto, sugerindo estar totalmente aderido a derme. Circundando o ducto, são encontradas glândulas mucosas diferenciadas (glândulas acessórias), com tamanho intermediário entre as glândulas mucosas e as granulosas (Figura 3).

As glândulas acessórias são compostas por células secretoras em forma de prisma, e encontram-se dispostas ao redor do ducto alveolar e imediatamente abaixo da epiderme envolta na camada esponjosa da derme, apresentando pequenos ductos de comunicação com o meio externo que transpassam a derme (Figura 3).

Cada alvéolo macroglandular corresponde a uma glândula sincicial de grandes dimensões, com aparência similar à das glândulas granulosas da pele. Os alvéolos não apresentam lúmen, pois os grânulos são produzidos no citoplasma sincicial e armazenados diretamente no interior do ácino (Figura 2C). Envolvendo o sincício secretor, existe uma camada delgada de células mioepiteliais. Essas células são caracterizadas por núcleos alongados semelhantes às células musculares lisas (Figura 2D). 
FIGURA 2: Prancha fotomicrográfica de secção transversal da glândula parotoide de Rhinella schneideri, evidenciando: (*) - Glândula mucosa; (G) - Glândula granulosa; (CC) - Camada Calcificada; (D) - Derme; (E) - Epiderme; (m) - Células mioepiteliais ao redor do alvéolo; (dA) - Ducto alveolar; (AL) - Alvéolo; $(\uparrow)$ - Ducto da glândula mucosa; (GA) - Glândula Acessória; (CE) - Camada Esponjosa; Coloração HE.
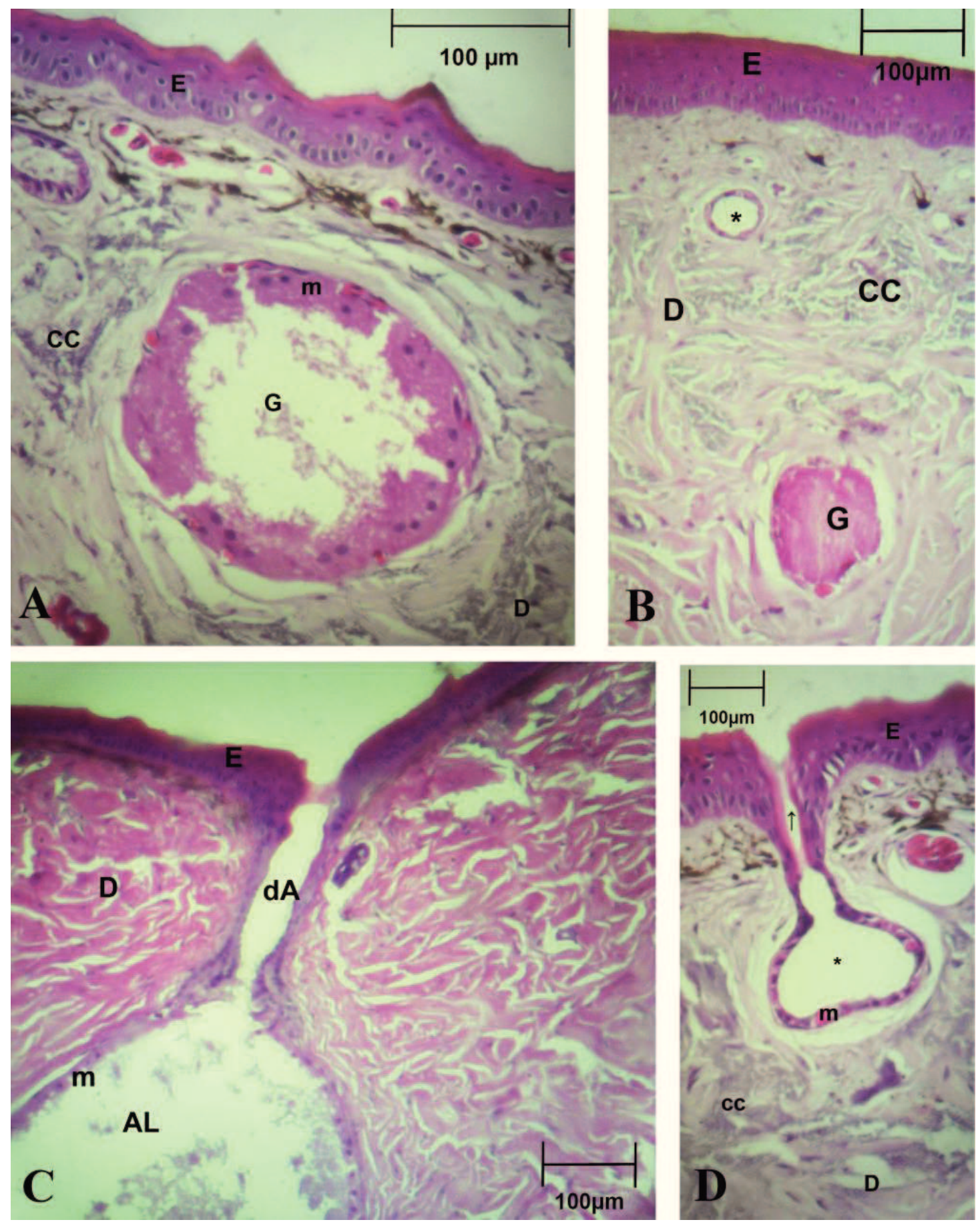
FIGURA 3: Fotomicrografia da secção transversal da glândula parotoide de Rhinella schneideri, evidenciando: (CC) - Camada Calcificada; (D) - Derme; (E) - Epiderme; (dA) - Ducto alveolar; (AL) - Alvéolo; ( $\uparrow$ - Ducto da Glândula Acessória; (GA) - Glândula Acessória e (CE) - Camada Esponjosa. Coloração HE.

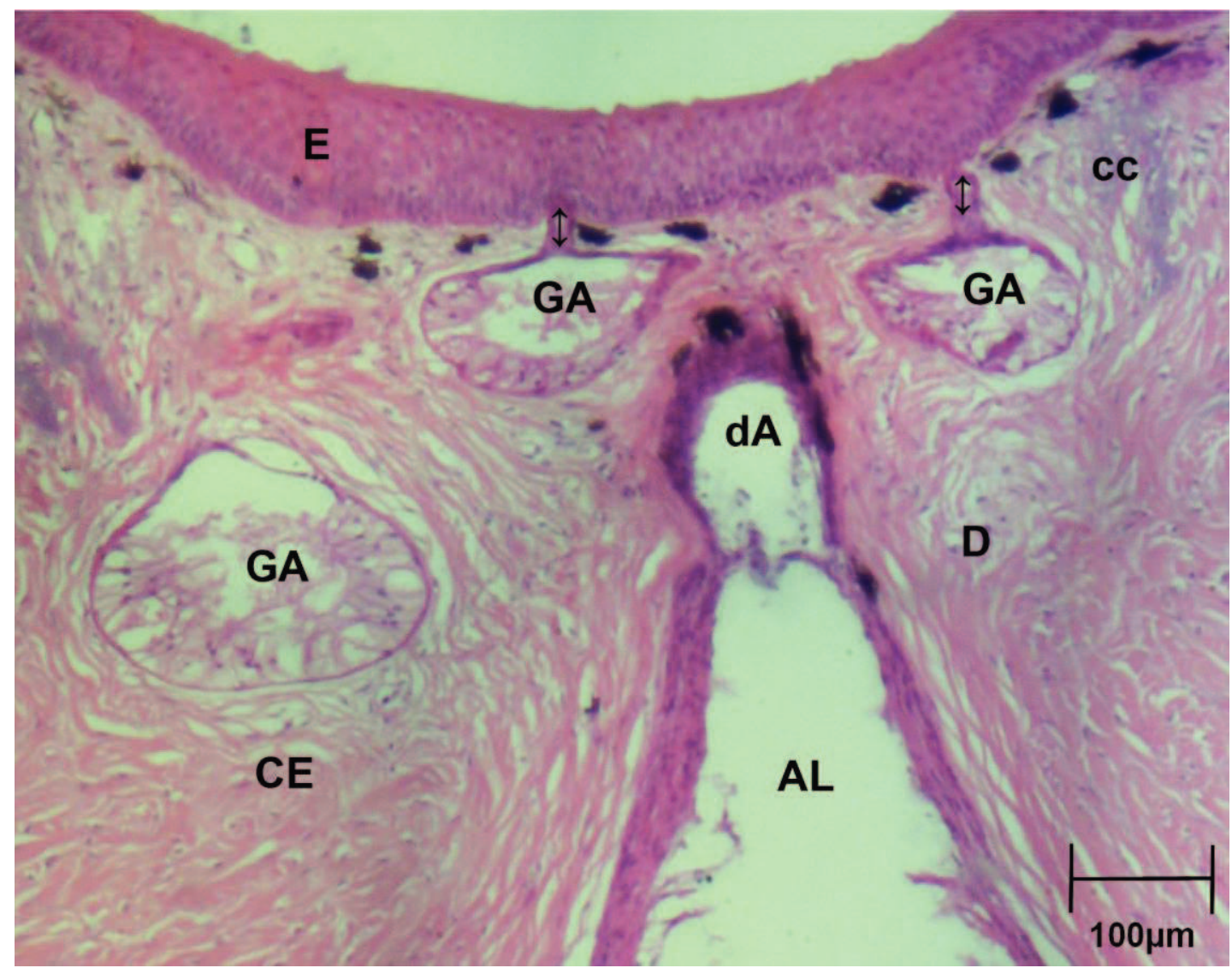

Foi observada também a presença de dois tipos de tecido conjuntivo: o tecido conjuntivo denso, que formam os septos entre cada alvéolo e que também constitui as paredes do assoalho das macroglândulas, e o tecido conjuntivo frouxo que preenche os espaços entre as paredes de cada alvéolo e o mioepitélio da unidade secretora.

\section{Discussão}

A partir dos dados observados em Rhinella schneideri, vimos que as macroglândulas estão relacionadas intimamente com os mecanismos de defesa, quando comparado com outras espécies, levando em consideração as divergências deste mecanismo entre diferentes espécies citados no texto.
Histologicamente, visualizou-se a camada da epiderme recobrindo as parotoides e a pele em toda a extensão corpórea. A derme é composta pelo estrato esponjoso, onde estão inseridas as glândulas mucosas, as quais são menores que as granulosas, não possuem lúmen e se distribuem por toda a pele situada abaixo da epiderme evidenciada na espécie Rhinella schneideri, assemelhando-se a Rhinella marina (FONTANA, 2012) e Rhinella ictericus (ALMEIDA et al., 2007). A camada calcificada dérmica dos anuros apresenta-se bastante desenvolvida e localizada na derme, abaixo das glândulas cutâneas e bem próximo a epiderme, característica apresentada na família Bufonidae descrita por Toledo et al. (1992) e Jared e Antoniazzi (2009), características histológicas semelhantes ao verificado para Rhinella schneideri. 
Em um estudo sobre as semelhanças observadas nas espécies Rhinella marina e Rhaebo guttatus, descrito por Lobo (2005), existem semelhanças estruturais em relação aos bufonídeos corroborando com a pesquisa do presente trabalho Rhinella schneideri.

Ao microscópio observa-se que os ductos são revestidos internamente por células epiteliais glandulares do próprio ducto, constituindo um plug, este descrito por Lobo (2005). Esses plugs são estruturas especializadas, constituídas de um material muito espesso e praticamente obstrui o lúmen do ducto, típicas das parotoides, que devem atuar no processo de expulsão do veneno, uma vez que funcionam como rolhas, mantendo a pressão interna dos alvéolos (LOBO, 2005; JARED; ANTONIAZZI, 2009). Observa-se também que esta camada de revestimento é unicelular diferentemente do descrito por Almeida et al. (2007) em Rhinella ictericus, que apresenta epitélio estratificado.

A presença de um revestimento mioepitelial nas glândulas alveolares, auxilia o entendimento do processo de excreção de seu conteúdo, como ocorre com a $R$. ictericus (ALMEIDA et al., 2007).

Circundando o ducto, são encontradas glândulas mucosas diferenciadas denominadas glândulas acessórias, segundo Jared e Antoniazzi (2009). Em outro estudo na espécie Rhinella marina as glândulas acessórias são compostas por células secretoras em forma de prisma (FONTANA, 2012), características estas encontradas em Rhinella schneideri.

Conclui-se que, as glândulas parotoides de Rhinella schneideri são semelhantes às de Rhinella marina bem como as de Rhaebo guttatus. Essas macroglândulas mostram semelhanças relacionadas aos alvéolos, com presença de ductos circundados com células mucosas diferenciadas, denominadas glândulas acessórias próximas aos alvéolos, sendo também encontradas glândulas granulosas e mucosas. Essas macroglândulas quando se comparado a outras espécies não apresentam diferenciação histológica em se tratando de aspectos morfológicos, contrariando no que diz respeito à composição das macroglândulas e mecanismo de defesa.

\section{Referências}

ALMEIDA, P. G.; FELSEMBURGH, F. A.; AZEVEDO, R. A.; BRITO-GITIRANA, L. Morphological re-evaluation of the parotoid glands of Bufo ictericus (Amphibia, Anura, Bufonidae). Contributions to Zoology, Amsterdam, v. 76, n. 3, p. 145-152, 2007 AQUINO, L.; REICHLE, S.; COLLI, G.; SCOTT, N.; LAVILLA, E.; LANGONE, J. Rhinella schneideri. The IUCN red list of threatened species. 2014. Disponível em: <www.iucnredlist.org>. Acesso em: 7 out. 2014.

AVMA PANEL ON EUTHANASIA. Report of the AVMA Panel on Euthanasia 2000. Journal of the American Veterinary Medical Association, Schaumburg, v. 218, p. 669-696, 2001.

BASTOS, R. P.; MOTTA, J. A. O.; LIMA, L. P.; GUIMARÃES, L. D. Anfíbios da Floresta Nacional de Silvânia, estado de Goiás. Goiânia: Stylo Gráfica e Editora, 2003. 29 p.

CFMV. Resolução no 1000, de 11 de Maio de 2012. Dispõe sobre procedimentos e métodos de eutanásia em animais, e dá outras providências. 2012. Diário Oficial da União. Brasil. Disponível em: <www.cfmv.org.br/portal/legislacao/resolucoes/resolucao_1000. pdf $>$. Acesso em: 7 out. 2014.

CLARKE, B. T. The natural history of amphibian skin secretions: Their normal functioning and potential medical applications. Biological Reviews, Cambridge v. 72, n. 3, p. 365-379, 1997.

DAPSON, R. W. Histochemistry of mucus in the skin of the frog Rana pipiens. Anatomical Record, Philadelphia, v. 166, n. 4, p. 615-625, 1970.

DELFINO, G. Ultrastructural aspects of venom secretion in anuran cutaneous glands. In: TU, A. T.; DEKKER, M. (Ed.). Reptile venoms and toxins. Handbook of natural toxins. New York: Marcel Dekker Inc, 1991. p. 777-802.

FONTANA, P. L. M. Estudo morfológico comparativo do sistema de defesa química cutânea em duas espécies de sapos amazônicos (Rhinella marina e Rhaebo guttatus). 2012. 103 f. Dissertação (Mestrado em Toxicologia) - Instituto Butantan, São Paulo. 2012.

FROST, D. Amphibian species of the world, an on line reference. 2011. Version 5.0. New York: American Museum of Natural History. Disponível em: <http://reserach.amnh.org/herpetology/ amphibia/index.php> Acesso em: 23 jul. 2014.

HADDAD, C. F. B.; ABE, A. S. Avaliação e ação prioritárias para a conservação da biodiversidade da Mata Atlântica e Campos Sulinos. Brasilia: MMA/SBF, 2000. 40 p.

JARED, C.; ANTONIAZZI, M. M. Anfíbios: biologia e seus venenos. In: CARDOSO, J. L. C.; FRANÇA, F. O. S.; FAN, W. H.; MÁLAQUE, C. M.; HADDAD JR, V. (Ed.). Animais peçonhentos no Brasil: biologia, clínica e terapêutica. 2. ed. São Paulo: Sauvier, 2009. p. 317-330.

LOBO, S. Macroglândulas parotóides de sapos (Anura: Bufonidae): um estudo integrativo. 2005. 83 f. Dissertação (Mestrado em Morfologia) - Universidade Federal de São Paulo, São Paulo. 2005.

RIBEIRO, R. DA S.; EGITO, G. T. DO; HADDAD, C. F. B. Chave de identificação: anfíbios anuros da vertente de Jundiaí da Serra do Japi, estado de São Paulo. Biota Neotropica, Campinas, v. 5, n. 2 , p. $235-247,2005$. 
TERRENI, A.; NOSI, D.; GREVEN, H.; DELFINO, G. Development of serous cutaneous glands in Scinax nasica (Anura, Hylidae): patterns of poisons biosynthesis and maturation with larval glands in specimens of other families. Tissue \& Cell, New York, v. 35, n. 4, p. 247-287, 2003.

TOLEDO, R. C.; JARED, C. Cutaneous granular glands and amphibian venoms. Comparative Biochemistry and Physiology, Salt Lake City, v. 111, p. 1-29, 1995.
TOLEDO, R. C.; JARED, C.; BRUNNER, A. Morfology of the large granular alveoli of toad (Bufo ictericus) parotoid glands before and after compression. Toxicon, Glasgow, v. 30, n. 7, p. 745-753, 1992.

VIEIRA, D. M. L. Taxonomia e filogenia molecular do grupo Rhinella margaritifera (Amphibia, Anura, Bufonidae) da Amazônia brasileira. 2010. 124 f. Dissertação (Mestrado em Genética, Conservação e Biologia Evolutiva) - Instituto Nacional de Pesquisas da Amazônia, Manaus, 2010. 